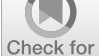

Check for

updates

Cite as

Nano-Micro Lett.

(2021) 13:66

Received: 15 October 2020

Accepted: 28 December 2020

Published online: 9 February 2021

(c) The Author(s) 2021

\section{Ultrathin, Lightweight, and Flexible CNT Buckypaper Enhanced Using MXenes for Electromagnetic Interference Shielding}

\author{
Rongliang Yang ${ }^{1}$, Xuchun Gui $^{1}{ }^{凶}, \mathrm{Li} \mathrm{Yao}^{2}$, Qingmei Hu${ }^{1}$, Leilei Yang ${ }^{1}$, Hao Zhang ${ }^{3}$, \\ Yongtao $\mathrm{Yao}^{4}$, Hui $\mathrm{Mei}^{2}{ }^{凶}$, Zikang Tang $^{5}$
}

\title{
HIGHLIGHTS
}

- Ultrathin, lightweight, and flexible carbon nanotube buckypaper enhanced using MXenes $\left(\mathrm{Ti}_{3} \mathrm{C}_{2} \mathrm{~T}_{\mathrm{x}}\right)$ for high-performance electromagnetic interference shielding is synthesized through facile electrophoretic deposition.

- The obtained $\mathrm{Ti}_{3} \mathrm{C}_{2} \mathrm{~T}_{\mathrm{x}} @ \mathrm{CNT}$ hybrid buckypaper demonstrates outstanding EMI shielding effectiveness of $60.5 \mathrm{~dB}$ in the X-band at $100 \mu \mathrm{m}$ and a specific SE value of $5.7 \times 10^{4} \mathrm{~dB} \mathrm{~cm}^{2} \mathrm{~g}^{-1}$ at $5 \mu \mathrm{m}$.

ABSTRACT Lightweight, flexibility, and low thickness are urgent requirements for next-generation high-performance electromagnetic interference (EMI) shielding materials for catering to the demand for smart and wearable electronic devices. Although several efforts have focused on constructing porous and flexible conductive films or aerogels, few studies have achieved a balance in terms of density, thickness, flexibility, and EMI shielding effectiveness (SE). Herein, an ultrathin, lightweight, and flexible carbon nanotube (CNT) buckypaper enhanced using MXenes $\left(\mathrm{Ti}_{3} \mathrm{C}_{2} \mathrm{~T}_{\mathrm{x}}\right)$ for high-performance EMI shielding is synthesized through a facile electrophoretic deposition process. The obtained $\mathrm{Ti}_{3} \mathrm{C}_{2} \mathrm{~T}_{\mathrm{x}} @ \mathrm{CNT}$ hybrid buckypaper exhibits an outstanding EMI SE of $60.5 \mathrm{~dB}$ in the X-band at $100 \mu \mathrm{m}$. The hybrid buckypaper with an MXene content of $49.4 \mathrm{wt} \%$ exhibits an EMI SE of $50.4 \mathrm{~dB}$ in the X-band with a thickness of only $15 \mu \mathrm{m}$, which is

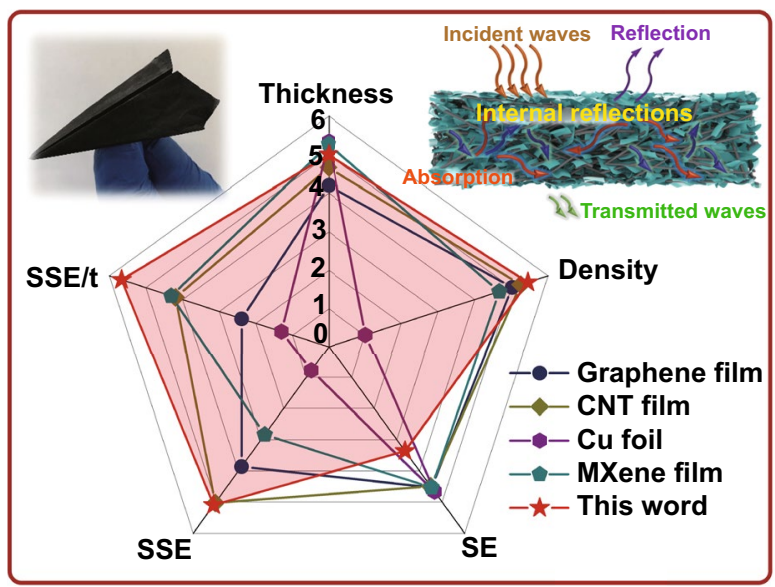

$105 \%$ higher than that of pristine CNT buckypaper. Furthermore, an average specific SE value of $5.7 \times 10^{4} \mathrm{~dB} \mathrm{~cm}^{2} \mathrm{~g}^{-1}$ is exhibited in the 5 - $\mu \mathrm{m}$ hybrid buckypaper. Thus, this assembly process proves promising for the construction of ultrathin, flexible, and high-performance EMI shielding films for application in electronic devices and wireless communications.

KEYWORDS Carbon nanotube; MXene; Buckypaper; Electromagnetic interference shielding

Xuchun Gui, guixch@mail.sysu.edu.cn; Hui Mei, phdhuimei@yahoo.com

${ }^{1}$ State Key Laboratory of Optoelectronic Materials and Technologies, School of Electronics and Information Technology, Sun Yat-Sen University, Guangzhou 510275, People's Republic of China

2 Science and Technology on Thermostructural Composite Materials Laboratory, School of Materials Science and Engineering, Northwestern Polytechnical University, Xi'an 710072, Shaanxi, People's Republic of China

3 Instrumental Analysis and Research Center (IARC), Sun Yat-Sen University, Guangzhou 510275, People's Republic of China

4 National Key Laboratory of Science and Technology on Advanced Composites in Special Environments, Harbin Institute of Technology, Harbin 150080, People's Republic of China

5 Institute of Applied Physics and Materials Engineering, University of Macau, Taipa 999078, Macau, People’s Republic of China 


\section{Introduction}

In the rapidly developing age of electronics, because the increasing amount of electromagnetic radiation pollution is damaging the stability of electronic equipment and even human health, high-performance electromagnetic interference (EMI) shielding materials are in great demand. Instead of traditional metal-based materials, next-generation EMI shielding materials are required and must be flexible, lightweight, and highly efficient. Carbon-based nanomaterials, including cellulose nanofibers $[1,2]$, carbon nanotubes (CNTs) [3-5], and graphene [6, 7], are widely considered as promising, flexible EMI shielding materials because of their low density, high conductivity, and high processability. For instance, the CNT sponge/epoxy composite exhibits an EMI shielding effectiveness (SE) of $33 \mathrm{~dB}$ in the X-band at $2 \mathrm{~mm}$ [3]. In addition, graphene/polydimethylsiloxane (PDMS) foam has shown a high EMI SE of $30 \mathrm{~dB}$ in the $\mathrm{X}$-band at a thickness of $1.0 \mathrm{~mm}$ [6]. To further decrease the density and improve the specific SE (SSE), CNTs or graphene have been directly used to construct shielding films with porous network structures [8-11]. For example, a graphene-based aerogel with a density of only $24.5 \mathrm{mg} \mathrm{cm}^{-3}$ showed a high EMI SE of $83 \mathrm{~dB}$ in the X-band at a thickness of $2.0 \mathrm{~mm}$ [10]. A free-standing CNT sponge with a density of $10.0 \mathrm{mg} \mathrm{cm}^{-3}$ exhibited a satisfactory EMI SE of $54.8 \mathrm{~dB}$ and an SSE of $5480 \mathrm{~dB} \mathrm{~cm}^{3} \mathrm{~g}^{-1}$ at a thickness of $1.8 \mathrm{~mm}$ [12]. Nevertheless, because absorption is the dominant EMI shielding mechanism in these carbon-based materials $[4,12]$, the shielding performance relies on the thickness of the samples. Almost all carbon-based nanomaterials are required to have a high thickness to achieve a high SE. The construction of a flexible high-performance EMI shielding material with a low thickness remains a challenge.

In the case of a limited thickness (resulting in limited absorption), improving the reflection is one of the most effective strategies to enhance the EMI performance. Many efforts are being focused on improving the conductivity and optimizing shielding material microstructures. All types of metallic nanoparticles [13], nanowires [14, 15], and nanosheets have been used to combine with carbon nanomaterials to achieve a high conductivity and thereby a high shielding performance with limited thickness. In particular, MXene nanosheets have attracted significant interest for EMI shielding owing to their metallic conductivity and unique two-dimensional (2D) structure [16-19]. Although densely packed MXene can exhibit a high EMI SE at a low thickness [20-25], dense MXene films may not satisfy the requirements of flexibility and low density owing to the weak interlayer interactions between MXene nanosheets $[26,27]$. Combining carbon nanomaterials with MXene is a promising strategy for balancing the mechanical properties and SE [1, 9, 28-30]. Recently, A reported flexible CNT/ MXene/cellulose nanofibril hybrid film exhibited a high conductivity of $2506.6 \mathrm{~S} \mathrm{~m}^{-1}$ and an SE of $38.4 \mathrm{~dB}$ in the $\mathrm{X}$-band at a thickness of $38 \mu \mathrm{m}$ [31]. Combined with MXene sheets, a highly dense graphene oxide film with a layered structure has shown an excellent SE of $50.2 \mathrm{~dB}$ at a low thickness of $7 \mu \mathrm{m}$ [32]. Nevertheless, because most of these studies have combined carbon materials with MXene via the mixing of their fragments through dispersion and obtained a shielding film using a spraying or filtration process, there are still several disadvantages to such films. First, although carbon materials and MXene nanosheets can be well dispersed in a solution, during the spraying or filtration process, the MXene nanosheets tend to self-stack when the solvent decreases. Although some reports have employed a layer-bylayer assembly method to avoid aggregation problems [26, 33-35], this is a complicated process. Second, the filtration process for 2D materials is time-consuming and unsuitable for large-scale production. Finally, the nanosheets are usually connected through a hydrogen bond or Van der Waals forces. These connections may not be sufficiently stable to withstand harsh situations. Thus, a more efficient assembly process for a carbon-based/MXene EMI shielding film should be developed.

Here, a simple assembly process is developed for fabricating a flexible MXene-enhanced CNT buckypaper with a satisfactory EMI SE within a small thickness. Pristine CNT buckypaper consisting of a porous and continuous CNT network is obtained via a typical chemical vapor deposition (CVD) process. After a simple rolling process, the compressed CNT buckypaper is observed to show a high SE of $49.8 \mathrm{~dB}$ in the X-band at a thickness of $100 \mu \mathrm{m}$, which is higher than that of most of the reported carbon materials. After a facile electrophoretic deposition process, the MXene $\left(\mathrm{Ti}_{3} \mathrm{C}_{2} \mathrm{~T}_{\mathrm{x}}\right)$ nanoflakes infiltrate into the CNT network and wrap around the CNT skeleton. The homogeneously distributed $\mathrm{Ti}_{3} \mathrm{C}_{2} \mathrm{~T}_{\mathrm{x}}$ nanoflakes are tightly connected to the CNTs, resulting in a higher shielding performance than that of the randomly stacked $\mathrm{Ti}_{3} \mathrm{C}_{2} \mathrm{~T}_{\mathrm{x}} / \mathrm{CNT}$ composite. The obtained 
$\mathrm{Ti}_{3} \mathrm{C}_{2} \mathrm{~T}_{\mathrm{x}} @ \mathrm{CNT}$ hybrid buckypaper exhibits an outstanding SE of $60.5 \mathrm{~dB}$ in the X-band at a thickness of $100 \mu \mathrm{m}$. Moreover, the shielding performance of the hybrid buckypaper can be easily adjusted by changing the thickness and MXene content. The ultrathin $15-\mu \mathrm{m}$ hybrid buckypaper with 49.4 wt $\% \mathrm{Ti}_{3} \mathrm{C}_{2} \mathrm{~T}_{\mathrm{x}}$ exhibits an SE of $50.4 \mathrm{~dB}$ in the X-band, which is $105 \%$ higher than that of CNT buckypaper. In addition, an average specific SE (SSE/t) value of $56,945.8 \mathrm{~dB} \mathrm{~cm}^{2} \mathrm{~g}^{-1}$ is exhibited in the 5- $\mu \mathrm{m}$ hybrid buckypaper. Thus, the novel hybrid film is a promising high-performance EMI shielding material.

\section{Experimental Section}

\subsection{Synthesis of CNT Buckypaper}

A traditional CVD method was used to synthesize the freestanding and flexible CNT buckypaper, for which a solution of ferrocene and dichlorobenzene was used as a carbon source. The flow rate of the carrying gas was set as $2000 / 300 \mathrm{sccm}$ of $\mathrm{Ar} / \mathrm{H}_{2}$, and the growth temperature was set as $860^{\circ} \mathrm{C}$. Through setting the growth time, CNT buckypapers with a series of thicknesses from 0.1 to $2.0 \mathrm{~mm}$ were obtained. Then, a simple rolling process was used to densify the CNT buckypapers, the densities of which increased from $\sim 10$ to $\sim 500 \mathrm{mg} \mathrm{cm}^{-3}$. Accordingly, the thickness decreased to $5-100 \mu \mathrm{m}$.

\subsection{Synthesis of $\mathrm{Ti}_{3} \mathrm{C}_{2} \mathrm{~T}_{\mathrm{x}}$ Nanosheets}

The typical selective etching process was used to obtain MXene $\left(\mathrm{Ti}_{3} \mathrm{C}_{2} \mathrm{~T}_{\mathrm{x}}\right)$ nanosheets from the MAX phase precursor $\left(\mathrm{Ti}_{3} \mathrm{AlC}_{2}\right)$. In a polytetrafluoroethylene container, $2 \mathrm{~g}$ of $\mathrm{LiF}$ powder was added to $20 \mathrm{~mL}$ of $9 \mathrm{M} \mathrm{HCl}$ solution. Subsequently, at a constant temperature of $35^{\circ} \mathrm{C}, 1 \mathrm{~g}$ of $\mathrm{Ti}_{3} \mathrm{AlC}_{2}$ powder was slowly added to the container, followed by continuous stirring. After a 24-h reaction, the reactant was centrifugally washed several times, until the $\mathrm{pH}>6$. The obtained sediment was collected and dispersed in DI water again with 1-h sonication in an ice bath and flowing argon atmosphere. Finally, after dilution and centrifugal separation at $8000 \mathrm{rpm}$ several times, the dark green $\mathrm{Ti}_{3} \mathrm{C}_{2} \mathrm{~T}_{\mathrm{x}}$ nanosheet supernatant was collected.

\subsection{Synthesis of $\mathrm{Ti}_{3} \mathrm{C}_{2} \mathrm{~T}_{\mathrm{x}} @ \mathrm{CNT}$ Hybrid Buckypaper}

The $\mathrm{Ti}_{3} \mathrm{C}_{2} \mathrm{~T}_{\mathrm{x}} @ \mathrm{CNT}$ hybrid buckypaper was prepared through a simple electrophoretic deposition process. As the working electrode, the as-grown porous CNT buckypapers with different thicknesses $(0.1-2.0 \mathrm{~mm})$ were cut into regular squares, while $\mathrm{Pt}$ was used as the counter electrode, and $1.0 \mathrm{mg} \mathrm{mL}^{-1} \mathrm{Ti}_{3} \mathrm{C}_{2} \mathrm{~T}_{\mathrm{x}}$ aqueous dispersion was used as the electrolyte. With a controlled applied constant voltage $(10 \mathrm{~V})$ and reaction time (10-120 $\mathrm{min})$, a series of $\mathrm{Ti}_{3} \mathrm{C}_{2} \mathrm{~T}_{\mathrm{x}} @ \mathrm{CNT}$ hybrids were obtained, after which they were vacuum dried at $50{ }^{\circ} \mathrm{C}$ for $12 \mathrm{~h}$. Finally, the hybrids were densified through the same rolling process to obtain the $\mathrm{Ti}_{3} \mathrm{C}_{2} \mathrm{~T}_{\mathrm{x}} @ \mathrm{CNT}$ hybrid buckypapers, the thicknesses of which decreased to $5-100 \mu \mathrm{m}$.

\subsection{Characterization}

The microstructures and morphologies of the $\mathrm{Ti}_{3} \mathrm{C}_{2} \mathrm{~T}_{\mathrm{x}}$ nanosheets, CNT buckypaper, and $\mathrm{Ti}_{3} \mathrm{C}_{2} \mathrm{~T}_{\mathrm{x}} @ \mathrm{CNTs}$ hybrid buckypaper were characterized using scanning electron microscopy (SEM, Hitachi, S-4800) and transmission electron microscopy (TEM, Tecnai, F30). The composition ratio in the hybrid buckypaper was tested through thermogravimetric analysis (TGA, Netzsch, TG209 F1). The crystal structures, ingredient information, and chemical bonds in the samples were measured using X-ray photoelectron spectroscopy (XPS, Thermo Scientific, ESCALAB 250Xi), $\mathrm{X}$-ray powder diffraction (XRD, Empyrean), and the Raman spectra (HORIBA, LabRAM HR). The EMI SE was determined using a vector network analyzer (Agilent Technologies, N5234A) within the frequency range of 8-12 GHz. The electrical conductivity of the samples was measured using a Keithley 2400.

\section{Results and Discussion}

\subsection{Shielding Performance of CNT Buckypaper}

Free-standing, flexible CNT buckypapers consisting of porous and continuous CNT networks were synthesized through a well-controlled CVD process. A simple rolling process was used to densify the CNT buckypapers (Fig. $\mathrm{S} 1$ ), in which process the densities of the CNT buckypaper 
increased from $\sim 10$ to $\sim 500 \mathrm{mg} \mathrm{cm}{ }^{-3}$, and the thickness decreased from $0.1-2.0 \mathrm{~mm}$ to $5-100 \mu \mathrm{m}$. The interconnected CNTs ensured that the CNT network endured a complex change in shape. A high structural stability and flexibility are demonstrated in the densified films. The films can be folded into a "paper plane" without undergoing any breaks or tears, as shown in Fig. 1a. The continuous CNT network also leads to satisfactory electronic transmission performance. A high electrical conductivity of $\sim 7000 \mathrm{~S}$ $\mathrm{m}^{-1}$ was observed in the densified films. The highly conductive network endows CNT buckypaper with satisfactory EMI shielding performance. The total $\mathrm{SE}\left(\mathrm{SE}_{\mathrm{Total}}\right)$ shows an evident increase with the added film thickness (Fig. 1b). Over the entire $\mathrm{X}$-band, the average $\mathrm{SE}_{\mathrm{Total}}$ of the 5- $\mu \mathrm{m}$ CNT buckypaper is $15.4 \mathrm{~dB}$, whereas that of the $100-\mu \mathrm{m}$ CNT buckypaper increases to a high value of $49.8 \mathrm{~dB}$. To further discuss the EMI shielding mechanism in the samples, the EMI reflection $\left(\mathrm{SE}_{\mathrm{R}}\right)$ and EMI absorption $\left(\mathrm{SE}_{\mathrm{A}}\right)$ over the $\mathrm{X}$-band have also been investigated. As shown in Fig. S2, all samples with different thicknesses exhibit strong microwave absorption in the X-band. With an increase in thickness, the average $\mathrm{SE}_{\mathrm{A}}$ shows a distinctly rising trend, whereas the $\mathrm{SE}_{\mathrm{R}}$ grows quite slowly (Fig. 1c). These trends demonstrate an absorption-dominant mechanism in CNT buckypaper, and the reflection loss needs to be improved. The high absorption ratio may be attributed to the dense and porous network structure. $\mathrm{SE}_{\mathrm{Total}}$ data of more CNT buckypaper with different thicknesses are shown in Fig. S2e, which further indicates the adjustability in the shielding performance of the CNT buckypaper. The free-standing CNT buckypaper synthesized in this work shows a high EMI shielding performance among all carbon nanomaterials. However, there is still plenty of room for improvement.

\subsection{Synthesis and Characterization of $\mathbf{T i}_{3} \mathbf{C}_{2} \mathbf{T}_{\mathbf{x}} @ \mathbf{C N T}$ Hybrid Buckypaper}

MXene $\left(\mathrm{Ti}_{3} \mathrm{C}_{2} \mathrm{~T}_{\mathrm{x}}\right)$ nanosheets were used to enhance the CNT buckypaper for EMI shielding. As illustrated in Fig. 2a, a simple and novel electrophoretic deposition process was used to prepare the $\mathrm{Ti}_{3} \mathrm{C}_{2} \mathrm{~T}_{\mathrm{x}} @ \mathrm{CNT}$ hybrid buckypaper. During this process, the free-standing and porous CNT buckypaper was used as the working electrode and supporter, whereas $\mathrm{Ti}_{3} \mathrm{C}_{2} \mathrm{~T}_{\mathrm{x}}$ nanosheets dispersed in water were employed as fillers. As the fillers, $\mathrm{Ti}_{3} \mathrm{C}_{2} \mathrm{~T}_{\mathrm{x}}$ nanosheets were obtained by selectively etching from the MAX phase precursor $\left(\mathrm{Ti}_{3} \mathrm{AlC}_{2}\right)$. The exfoliated $\mathrm{Ti}_{3} \mathrm{C}_{2} \mathrm{~T}_{\mathrm{x}}$ nanosheets show a structure with a few layers, $\sim 5 \mathrm{~nm}$ in thickness and a mean size of several hundred nanometers to several micrometers (Figs. 2b and S3a). The crystal structure of the $\mathrm{Ti}_{3} \mathrm{C}_{2} \mathrm{~T}_{\mathrm{x}}$ nanosheet was further investigated through XRD patterns (Fig. S3b). When compared with that of $\mathrm{Ti}_{3} \mathrm{AlC}_{2}$, the characteristic peak (002) of $\mathrm{Ti}_{3} \mathrm{C}_{2} \mathrm{~T}_{\mathrm{x}}$ clearly shifts from $2 \theta=9.5^{\circ}$ to $2 \theta=5.7^{\circ}$, revealing the removal of $\mathrm{Al}$ layers and, thereby, enlargement of the c-lattice parameter in the $\mathrm{Ti}_{3} \mathrm{C}_{2} \mathrm{~T}_{\mathrm{x}}[19,35]$. Moreover, after exfoliation, the (104) peak of $\mathrm{Ti}_{3} \mathrm{C}_{2} \mathrm{~T}_{\mathrm{x}}$ at $2 \theta=39^{\circ}$ significantly decreases, which also indicates the successful selective etching of $\mathrm{Al}$ atoms and, thereby, decrease in the structural order. The exfoliated $\mathrm{Ti}_{3} \mathrm{C}_{2} \mathrm{~T}_{\mathrm{x}}$ nanosheets were further selected through centrifugal separation at $8000 \mathrm{rpm}$. The selected $\mathrm{Ti}_{3} \mathrm{C}_{2} \mathrm{~T}_{\mathrm{x}}$ nanosheets with smaller sizes were dispersed as $1.0 \mathrm{mg} \mathrm{mL}^{-1}$ aqueous
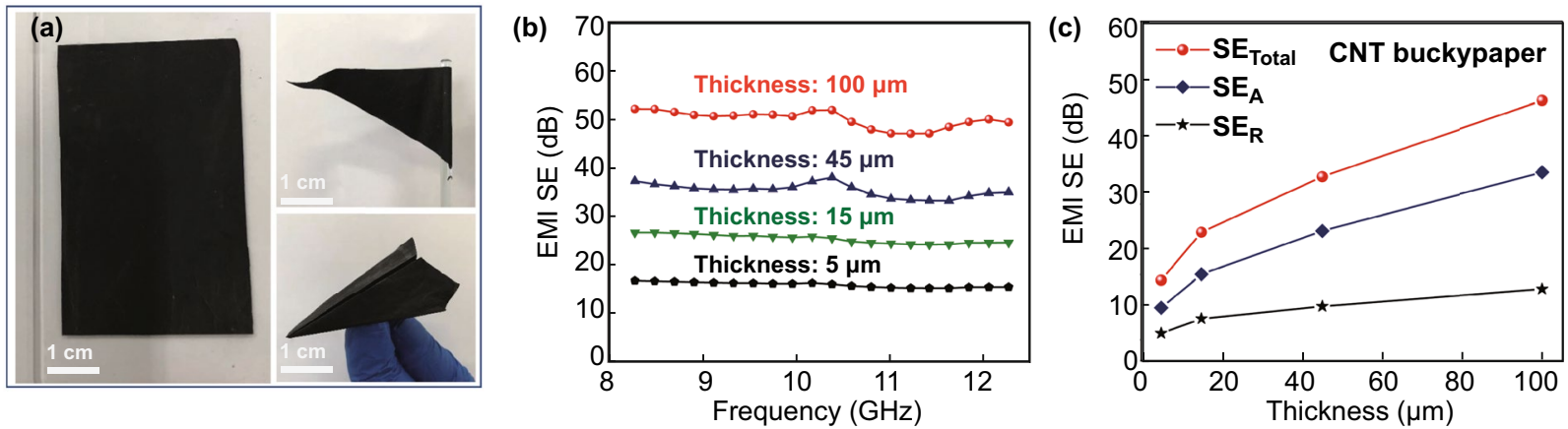

Fig. 1 EMI performance of CNT buckypaper. a Digital image of flat CNT buckypaper, rolled-up flag, and folded paper plane. b EMI SE of CNT buckypapers with different thickness in X-band region. c Comparison of average $\mathrm{SE}_{\mathrm{Tota}}, \mathrm{SE}_{\mathrm{A}}$, and $\mathrm{SE}_{\mathrm{R}}$ versus thickness of CNT buckypapers 


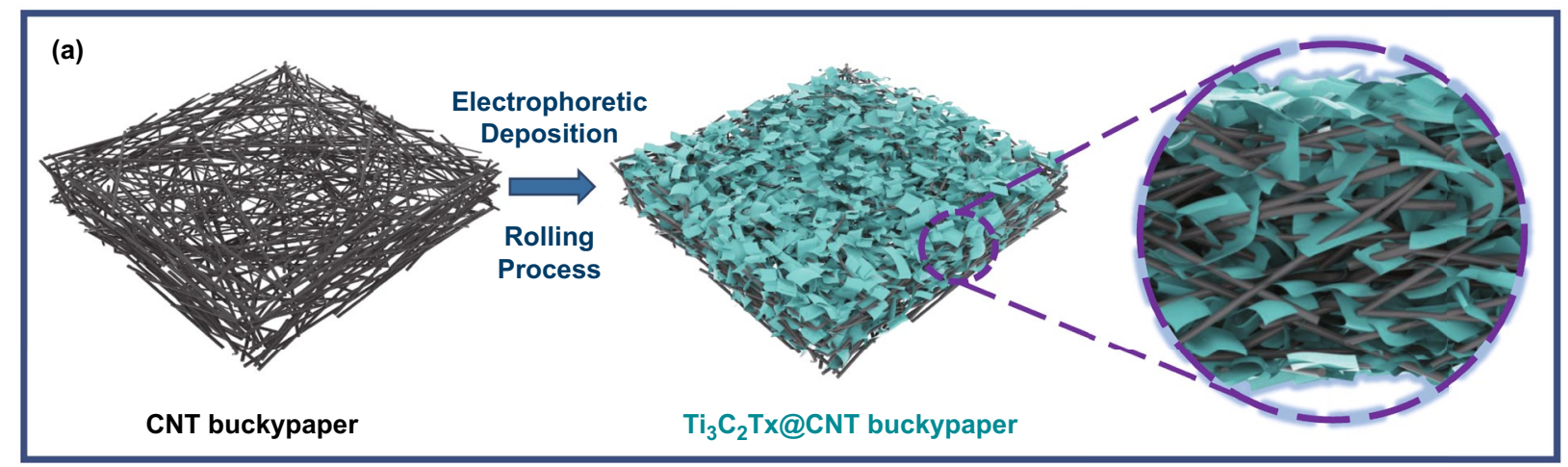

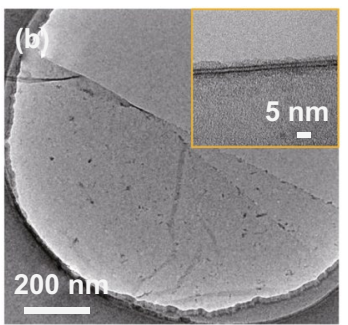

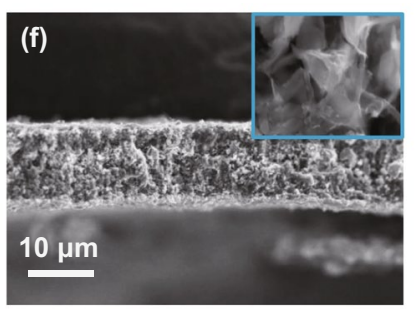

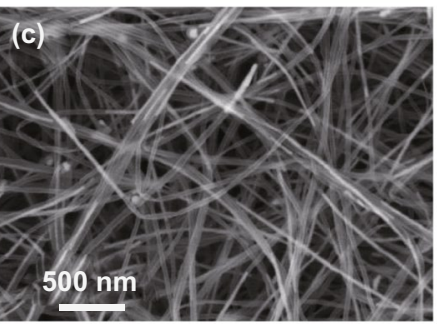

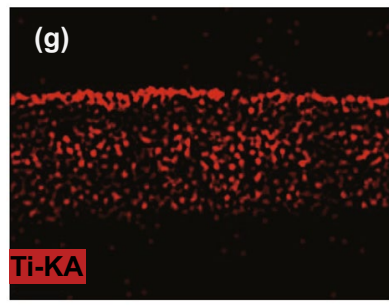

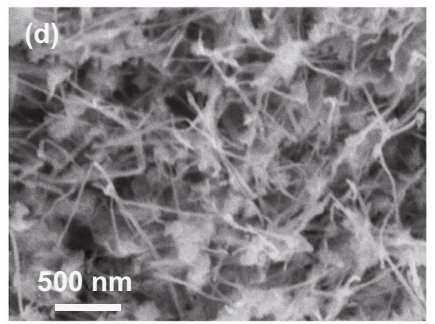
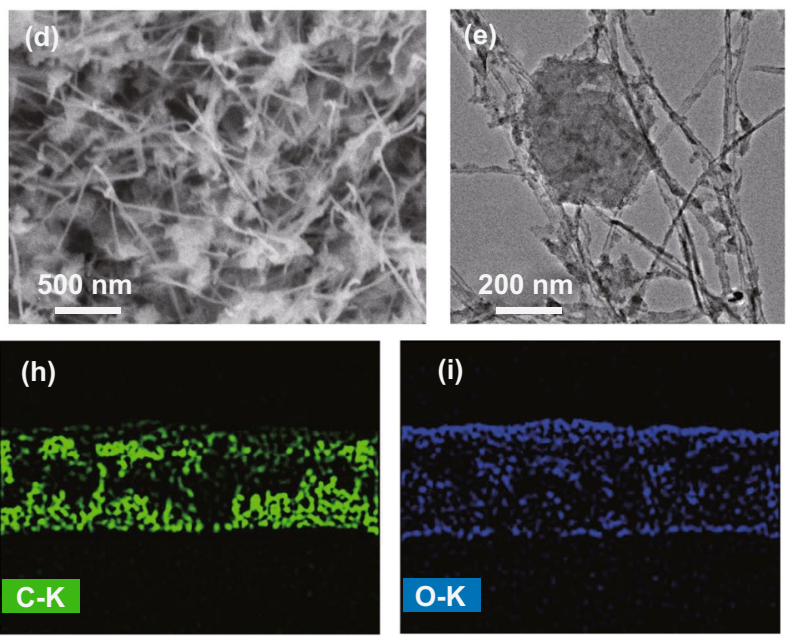

(i)

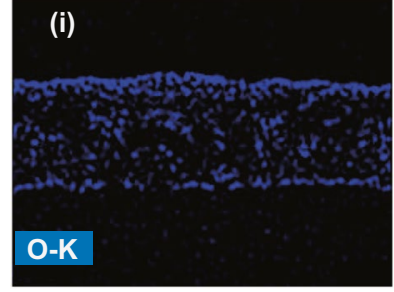

Fig. 2 Morphology of $\mathrm{Ti}_{3} \mathrm{C}_{2} \mathrm{~T}_{\mathrm{x}} @ \mathrm{CNT}$ hybrid buckypaper. a Schematic illustration of electrophoretic deposition process for fabrication of $\mathrm{Ti}_{3} \mathrm{C}_{2} \mathrm{~T}_{\mathrm{x}} @ \mathrm{CNT}$ hybrid buckypaper. b TEM image of $\mathrm{Ti}_{3} \mathrm{C}_{2} \mathrm{~T}_{\mathrm{x}}$ nanosheet (the inset shows the corresponding high-resolution TEM image). SEM image for interior of $\mathbf{c}$ CNT buckypaper and $\mathbf{d} \mathrm{Ti}_{3} \mathrm{C}_{2} \mathrm{~T}_{\mathrm{x}} @ \mathrm{CNT}$ hybrid buckypaper. e TEM image of $\mathrm{Ti}_{3} \mathrm{C}_{2} \mathrm{~T}_{\mathrm{x}} @ \mathrm{CNT}$ hybrid. f Cross-sectional SEM image of hybrid buckypaper (the inset shows the local details at high resolution). The corresponding EDS mapping images of $\mathbf{g}$ Ti, $\mathbf{h} \mathrm{C}$, and i O

dispersion (Fig. S4b), which showed a zeta potential of $-26.52 \mathrm{mV}$ (Fig. S4c). The size distribution results demonstrate that the diameters of the $\mathrm{Ti}_{3} \mathrm{C}_{2} \mathrm{~T}_{\mathrm{x}}$ nanosheets are concentrated around $288 \mathrm{~nm}$, which proves suitable for infiltration into the CNT network.

As the working electrode, the CNT buckypapers were full of pores, which allowed for the effective infiltration of the $\mathrm{Ti}_{3} \mathrm{C}_{2} \mathrm{~T}_{\mathrm{x}}$ nanoflakes (Fig. 2c). During the electrophoretic deposition process (Fig. S4a), when a certain voltage (10 V) was applied, the $\mathrm{Ti}_{3} \mathrm{C}_{2} \mathrm{~T}_{\mathrm{x}}$ nanosheets with negative charges in dispersion were forced to move toward the CNT buckypaper and finally infiltrate the carbon nanotube network. The size distributions of $\mathrm{Ti}_{3} \mathrm{C}_{2} \mathrm{~T}_{\mathrm{x}}$ nanoflakes around the two electrodes show that small-sized nanoflakes were firstly gathered at the CNT electrode (Fig. S4d). As the deposition process continues, the deposition process becomes stable.
Moreover, under the applied potential, both the carbon nanotubes and $\mathrm{Ti}_{3} \mathrm{C}_{2} \mathrm{~T}_{\mathrm{x}}$ nanosheets can be slightly etched, as proved in many reports [36-38]. The slightly unzipped and etched nanotube network provides a larger space for the infiltration of flakes, whereas the $\mathrm{Ti}_{3} \mathrm{C}_{2} \mathrm{~T}_{\mathrm{x}}$ nanosheets can also be fragmented into a smaller size. After electrophoretic deposition, the CNT buckypaper was covered with a uniform $\mathrm{Ti}_{3} \mathrm{C}_{2} \mathrm{~T}_{\mathrm{x}}$ layer and maintained its flexibility (Fig. S5a-c). Metalloid coatings can effectively enhance the reflection loss of electromagnetic waves. Meanwhile, the internal morphology of the $\mathrm{Ti}_{3} \mathrm{C}_{2} \mathrm{~T}_{\mathrm{x}} @ \mathrm{CNT}$ hybrid buckypaper clearly shows homogeneously distributed $\mathrm{Ti}_{3} \mathrm{C}_{2} \mathrm{~T}_{\mathrm{x}}$ inside the CNT network (Fig. 2d). The sizes of the inserted $\mathrm{Ti}_{3} \mathrm{C}_{2} \mathrm{~T}_{\mathrm{x}}$ nanoflakes are approximately tens to hundreds of nanometers, which can be further demonstrated in the TEM image (Fig. 2e). Cross-sectional SEM images and the related 
energy-dispersive spectrometry (EDS) mapping images further indicate the uniform distribution of $\mathrm{Ti}_{3} \mathrm{C}_{2} \mathrm{~T}_{\mathrm{x}}$ nanoflakes in a hybrid buckypaper (Fig. $2 \mathrm{f}-\mathrm{i}$ ). The inserted $\mathrm{Ti}_{3} \mathrm{C}_{2} \mathrm{~T}_{\mathrm{x}}$ nanoflakes can uniformly fill the entire CNT buckypaper (Fig. 2g). More details of the cross-sectional SEM image of the $\mathrm{Ti}_{3} \mathrm{C}_{2} \mathrm{~T}_{\mathrm{x}} @ \mathrm{CNT}$ hybrid buckypaper are shown in Fig. S5d-i. Both the inserted $\mathrm{Ti}_{3} \mathrm{C}_{2} \mathrm{~T}_{\mathrm{x}}$ nanoflakes and the CNT network formed a large number of micro-fissures. These separated nanoflakes and the formed micro-fissures greatly enhanced the internal multiple reflection and absorption of the film for electromagnetic waves. Moreover, the synthesized hybrid buckypapers were also densified via the same rolling process, in which $\mathrm{Ti}_{3} \mathrm{C}_{2} \mathrm{~T}_{\mathrm{x}} @ \mathrm{CNT}$ hybrid buckypapers with thicknesses of 5-100 $\mu \mathrm{m}$ were obtained.

The content of $\mathrm{Ti}_{3} \mathrm{C}_{2} \mathrm{~T}_{\mathrm{x}}$ nanoflakes in the hybrid buckypaper can be controlled by regulating the deposition time and applied voltage. In this work, with an applied voltage of $10 \mathrm{~V}$, the content of $\mathrm{Ti}_{3} \mathrm{C}_{2} \mathrm{~T}_{\mathrm{x}}$ can be effectively increased by extending the deposition time. For instance, for the $15-\mu \mathrm{m}$ samples, the content of $\mathrm{Ti}_{3} \mathrm{C}_{2} \mathrm{~T}_{\mathrm{x}}$ in the hybrid buckypaper is $9.2 \mathrm{wt} \%$ and $49.4 \mathrm{wt} \%$ after 10- and 120-min deposition, respectively, which can be calculated using the TG curves in air (Fig. 3a). Raman spectra further confirm the successful synthesis of the $\mathrm{Ti}_{3} \mathrm{C}_{2} \mathrm{~T}_{\mathrm{x}}$ nanoflakes and $\mathrm{Ti}_{3} \mathrm{C}_{2} \mathrm{~T}_{\mathrm{x}} @ \mathrm{CNT}$ hybrid buckypaper (Fig. 3b). The characteristic peak of Ti atoms at $199 \mathrm{~cm}^{-1}$ (corresponding to the out-of-plane vibrations) and that at $283 \mathrm{~cm}^{-1}$ (corresponding to the in-plane modes) can be found in both the $\mathrm{Ti}_{3} \mathrm{C}_{2} \mathrm{~T}_{\mathrm{x}}$ and $\mathrm{Ti}_{3} \mathrm{C}_{2} \mathrm{~T}_{\mathrm{x}} @ \mathrm{CNT}$ curves. Meanwhile, for the $\mathrm{Ti}_{3} \mathrm{C}_{2} \mathrm{~T}_{\mathrm{x}} @ \mathrm{CNTs}$, the two intense peaks at $1328 \mathrm{~cm}^{-1}$ (D band) and $1577 \mathrm{~cm}^{-1}$ (G band) can be related to the carbon nanotubes. These typical characteristic peaks indicate a good combination of $\mathrm{Ti}_{3} \mathrm{C}_{2} \mathrm{~T}_{\mathrm{x}}$ and CNTs. Detailed elemental chemical states in the $\mathrm{Ti}_{3} \mathrm{C}_{2} \mathrm{~T}_{\mathrm{x}} @ \mathrm{CNT}$ hybrid buckypaper were further investigated using XPS (Fig. S3c). Both the $\mathrm{Ti}_{3} \mathrm{C}_{2} \mathrm{~T}_{\mathrm{x}}$ and $\mathrm{Ti}_{3} \mathrm{C}_{2} \mathrm{~T}_{\mathrm{x}} @ \mathrm{CNT}$ hybrid buckypapers show distinct signals of $\mathrm{F}$ and $\mathrm{O}$, which are attributed to
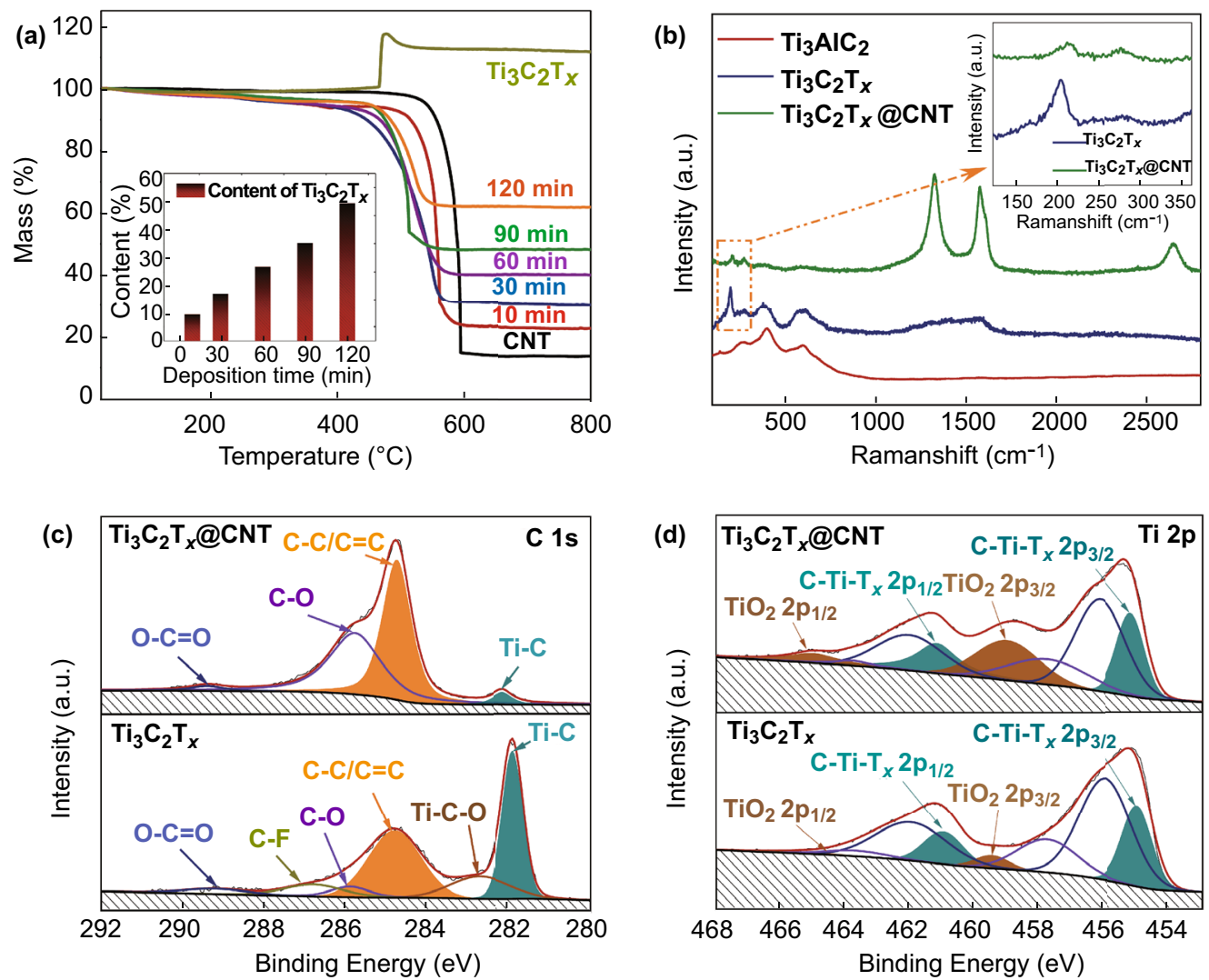

Fig. 3 Structural characterization of $\mathrm{Ti}_{3} \mathrm{C}_{2} \mathrm{~T}_{\mathrm{x}} @ \mathrm{CNT}$ hybrid buckypaper. a TG curves of $\mathrm{Ti}_{3} \mathrm{C}_{2} \mathrm{~T}_{\mathrm{x}}, \mathrm{CNT}$ buckypaper, and $\mathrm{Ti}_{3} \mathrm{C}_{2} \mathrm{~T}_{\mathrm{x}} @ \mathrm{CNT}$ hybrid buckypaper with different deposition time (the inset is the calculated content of $\mathrm{Ti}_{3} \mathrm{C}_{2} \mathrm{~T}_{\mathrm{x}}$ in hybrid buckypapers with a thickness of $15 \mu \mathrm{m}$ ). $\mathbf{b}$ Raman spectra of $\mathrm{Ti}_{3} \mathrm{AlC}_{2}, \mathrm{Ti}_{3} \mathrm{C}_{2} \mathrm{~T}_{\mathrm{x}}$, and $\mathrm{Ti}_{3} \mathrm{C}_{2} \mathrm{~T}_{\mathrm{x}} @ \mathrm{CNT}$ hybrid buckypaper (the inset is the partially enlarged spectra). High-resolution XPS spectra of $\mathbf{c} \mathrm{C} 1 s$ and $\mathbf{d}$ Ti $2 p$ for $\mathrm{Ti}_{3} \mathrm{C}_{2} \mathrm{~T}_{\mathrm{x}}$ and $\mathrm{Ti}_{3} \mathrm{C}_{2} \mathrm{~T}_{\mathrm{x}} @ \mathrm{CNT}$ hybrid buckypaper 
surface terminations such as $-\mathrm{F},-\mathrm{OH}$, and $-\mathrm{O}$ [39]. Among them, the slightly increased $\mathrm{O} 1 s$ signal in the $\mathrm{Ti}_{3} \mathrm{C}_{2} \mathrm{~T}_{\mathrm{x}} @$ CNT hybrid originates from the minor oxidation during the electrophoretic deposition process. To confirm the chemical bonding in the $\mathrm{Ti}_{3} \mathrm{C}_{2} \mathrm{~T}_{\mathrm{x}} @ \mathrm{CNT}$ hybrid, high-resolution $\mathrm{C} 1 s$ and Ti $2 p$ spectra were further studied (Fig. 3c, d). In the $\mathrm{C} 1 s$ spectra, the sharply increased $\mathrm{C}-\mathrm{C} / \mathrm{C}=\mathrm{C}$ signal $(284.8 \mathrm{eV})$ in the $\mathrm{Ti}_{3} \mathrm{C}_{2} \mathrm{~T}_{\mathrm{x}} @ \mathrm{CNT}$ hybrid originates from the combination of $\mathrm{Ti}_{3} \mathrm{C}_{2} \mathrm{~T}_{\mathrm{x}}$ with carbon nanotubes. Meanwhile, in the Ti $2 p$ spectra, the Ti-C doublet peak $(455.0 \mathrm{eV}$ and $461.0 \mathrm{eV}$ ) remains almost constant in the $\mathrm{Ti}_{3} \mathrm{C}_{2} \mathrm{~T}_{\mathrm{x}} @$ CNT hybrid, whereas the $\mathrm{TiO}_{2}$ doublet peak $(459.5 \mathrm{eV}$ and $465.5 \mathrm{eV}$ ) increases slightly. The added oxygen signal in the $\mathrm{Ti}_{3} \mathrm{C}_{2} \mathrm{~T}_{\mathrm{x}} @ \mathrm{CNT}$ hybrid is mainly attributed to oxidized carbon.

\subsection{Shielding Performance of $\mathrm{Ti}_{3} \mathrm{C}_{2} \mathrm{~T}_{\mathbf{x}} @ \mathrm{CNT}$ Hybrid Buckypaper}

To investigate the influence of filling $\mathrm{Ti}_{3} \mathrm{C}_{2} \mathrm{~T}_{\mathrm{x}}$ on EMI SE, $\mathrm{Ti}_{3} \mathrm{C}_{2} \mathrm{~T}_{\mathrm{x}} @ \mathrm{CNT}$ hybrid buckypapers with various thicknesses were synthesized through a fixed electrophoretic deposition time (30 min). After the deposition process, all hybrids remained at almost the same thickness as that of the pristine CNT buckypapers. After the rolling process, the prepared 100- $\mu \mathrm{m}$ hybrid buckypaper exhibited a high average $\mathrm{SE}_{\text {Total }}$ of $60.5 \mathrm{~dB}$ within the $\mathrm{X}$-band region (Fig. 4a). Although absorption was still the main shielding mechanism in hybrid buckypapers, its reflection loss ratio increased to $31 \%$. Detailed EMI SE curves of hybrid buckypapers with various thicknesses within the $\mathrm{X}$-band are shown in Figs. $4 \mathrm{~b}$ and $\mathrm{S} 6 \mathrm{a}-\mathrm{d}$. The $\mathrm{SE}_{\text {Total }}, \mathrm{SE}_{\mathrm{R}}$, and $\mathrm{SE}_{\mathrm{A}}$ values in the hybrid buckypapers all show increasing trends with the added thickness, which are similar to those of the pristine CNT buckypapers (Fig. 4c). The enhanced reflection may be attributed to the MXene coating and increase the electrical conductivity, whereas the enhanced absorption may contribute to interface polarization and internal reflection.

A comparison of the SE between the $\mathrm{Ti}_{3} \mathrm{C}_{2} \mathrm{~T}_{\mathrm{x}} @ \mathrm{CNT}$ hybrid buckypapers and pristine CNT buckypapers is shown in Figs. 4d and S6. An approximate increase in the SE values is observed in samples with different thicknesses. The
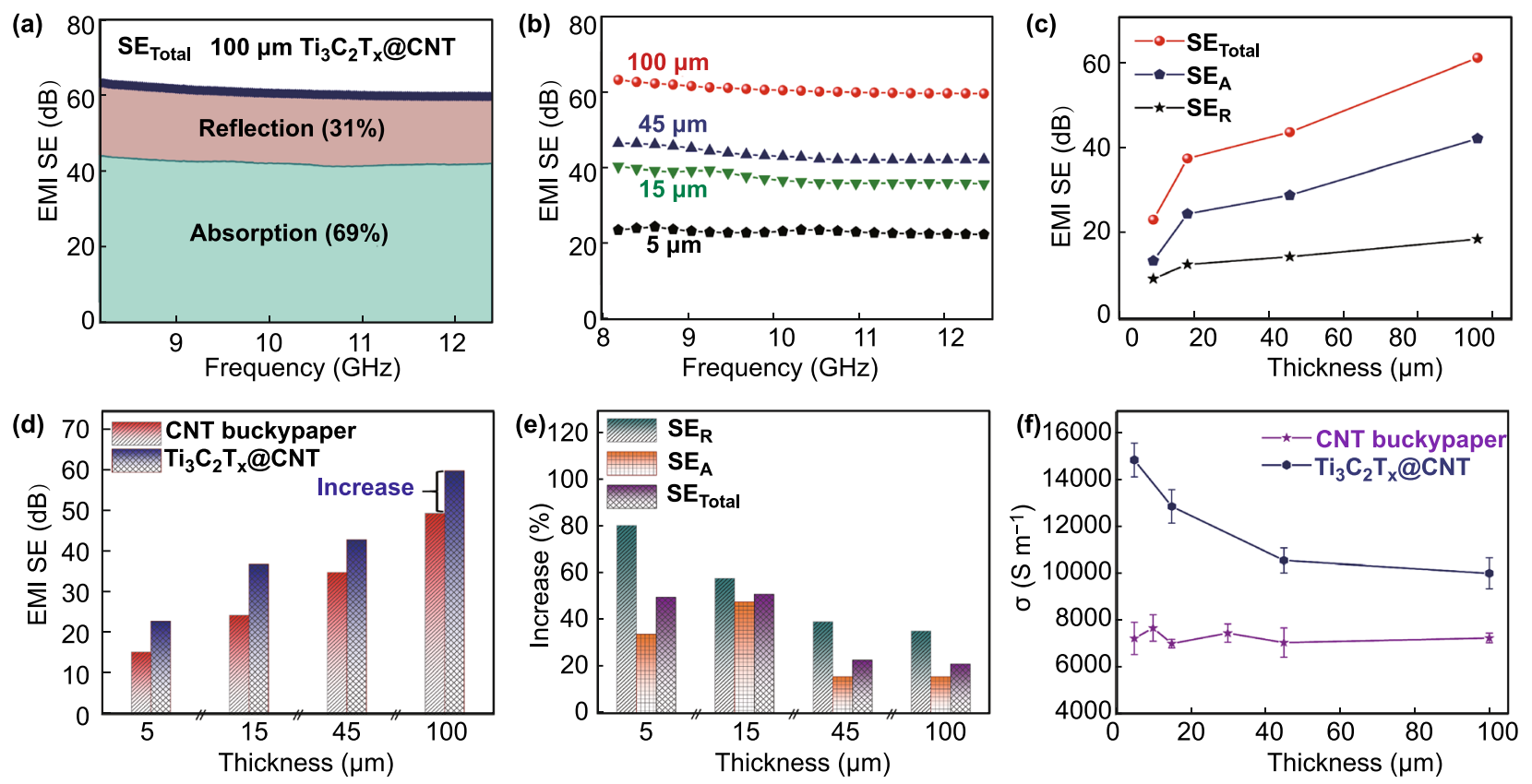

Fig. 4 EMI performance of $\mathrm{Ti}_{3} \mathrm{C}_{2} \mathrm{~T}_{\mathrm{x}} @ \mathrm{CNT}$ hybrid buckypaper with different thickness. a EMI SE of 100- $\mu$ m hybrid buckypaper (the SE includes the reflection and absorption parts). b EMI SE of the hybrid buckypapers with different thickness. c Average $\mathrm{SE}_{\mathrm{Total}}, \mathrm{SE}_{\mathrm{A}}$, and $\mathrm{SE}_{\mathrm{R}}$ versus thickness for $\mathrm{Ti}_{3} \mathrm{C}_{2} \mathrm{~T}_{\mathrm{x}} @ \mathrm{CNT}$ hybrid buckypapers. $\mathbf{d}$ Comparison of average $\mathrm{SE}_{\mathrm{Total}}$ versus thickness between CNT buckypapers and the hybrid buckypapers. e The increasing ratio of average $\mathrm{SE}_{\text {Total }}, \mathrm{SE}_{\mathrm{A}}$, and $\mathrm{SE}_{\mathrm{R}}$ versus thickness in $\mathrm{Ti}_{3} \mathrm{C}_{2} \mathrm{~T}_{\mathrm{x}} @ \mathrm{CNT}$ hybrid buckypapers (compared with the pristine CNT buckypaper). f Comparison of electrical conductivities versus thickness between CNT buckypaper and the hybrid buckypapers 
$15-\mu \mathrm{m}$ hybrid buckypaper presents a 12.6-dB increase in $\mathrm{SE}_{\text {Total }}$, whereas the $100-\mu \mathrm{m}$ sample shows a 10.6 -dB increment. Thus, for the hybrid buckypapers with various thicknesses, the electrophoretic deposition processes with fixed deposition time contributed to efficient and stable enhancements in the shielding performance. Nevertheless, because the CNT buckypapers with small thicknesses show a significantly lower SE, a higher increasing ratio appears in thinner samples (Fig. 4e). For instance, when compared with the pristine CNT buckypaper, the 5 - $\mu \mathrm{m}$ hybrid buckypaper presents an increasing ratio of $80.8 \%$ on $\mathrm{SE}_{\mathrm{R}}$. Meanwhile, for the $100-\mu \mathrm{m}$ hybrid buckypaper, the increasing ratio of $\mathrm{SE}_{\mathrm{R}}$ is only $35.5 \%$. It should be noted that when compared with the $15-\mu \mathrm{m}$ hybrid buckypaper, the 5- $\mu \mathrm{m}$ sample shows a higher increasing ratio on $\mathrm{SE}_{\mathrm{R}}$ but a lower ratio on $\mathrm{SE}_{\mathrm{A}}$ and $\mathrm{SE}_{\text {Total }}$. This indicates that the deposition of $\mathrm{Ti}_{3} \mathrm{C}_{2} \mathrm{~T}_{\mathrm{x}}$ nanoflakes for 30 min may overfill the 5 - $\mu \mathrm{m}$-thick CNT network. The excessively stacked nanoflakes formed a high-reflection coating. The CNT buckypaper with an excessively small thickness has a relatively low EMI SE and may be unsuitable for a long-time deposition. Thus, the $15-\mu \mathrm{m}$ CNT buckypaper is considered to be a suitable substrate for construction of an ultrathin and high-performance EMI shielding film. Meanwhile, the significantly increased electrical conductivity of the $\mathrm{Ti}_{3} \mathrm{C}_{2} \mathrm{~T}_{\mathrm{x}} @ \mathrm{CNT}$ hybrid buckypaper further confirms the significant contribution of the filling of $\mathrm{Ti}_{3} \mathrm{C}_{2} \mathrm{~T}_{\mathrm{x}}$ nanoflakes to the shielding performance (Fig. 4f). Because the pristine CNT buckypapers with different thicknesses have an approximate density, similar electrical conductivities from 7030 to $7704 \mathrm{~S} \mathrm{~m}^{-1}$ are presented in different CNT buckypapers. After the electrophoretic deposition process, the electrical conductivities of the hybrid films showed a distinct increase. The 100- $\mu \mathrm{m}$ hybrid buckypaper exhibits a high conductivity of $10,062 \mathrm{~S} \mathrm{~m}^{-1}$, which is $38.4 \%$ higher than that of the pristine CNT buckypaper. The highest conductivity of 14,933 $\mathrm{S} \mathrm{m}^{-1}$ was observed in the 5- $\mu \mathrm{m}$ sample, which is $105.8 \%$ higher than that of the pristine CNT buckypaper. This also confirms that the same filling of the $\mathrm{Ti}_{3} \mathrm{C}_{2} \mathrm{~T}_{\mathrm{x}}$ content contributes to a higher improvement in electrical conductivity and thereby a higher EMI SE in thinner hybrid films.

To construct an ultrathin and high-performance EMI shielding material, $\mathrm{Ti}_{3} \mathrm{C}_{2} \mathrm{~T}_{\mathrm{x}} @ \mathrm{CNT}$ hybrid buckypapers with various MXene contents at a small thickness $(15 \mu \mathrm{m})$ were further investigated. The 15- $\mu \mathrm{m} \mathrm{Ti}_{3} \mathrm{C}_{2} \mathrm{~T}_{\mathrm{x}} @ \mathrm{CNT}$ hybrid buckypapers with various $\mathrm{Ti}_{3} \mathrm{C}_{2} \mathrm{~T}_{\mathrm{x}}$ contents were synthesized by regulating the deposition time. Detailed EMI SE curves of the hybrid buckypapers with various $\mathrm{Ti}_{3} \mathrm{C}_{2} \mathrm{~T}_{\mathrm{x}}$ contents in the X-band are shown in Figs. 5a and S7a-e. The hybrid buckypapers with higher $\mathrm{Ti}_{3} \mathrm{C}_{2} \mathrm{~T}_{\mathrm{x}}$ contents exhibited significant improvements in EMI shielding performance. When the $\mathrm{Ti}_{3} \mathrm{C}_{2} \mathrm{~T}_{\mathrm{x}}$ content in the hybrid buckypaper increases from 9.2 to $49.4 \mathrm{wt} \%$, the average $\mathrm{SE}_{\text {Total }}$ increases from 29.3 to $50.4 \mathrm{~dB}$ (Fig. 5b). When compared with the pristine CNT buckypaper, the hybrid buckypaper with $49.4 \mathrm{wt} \% \mathrm{Ti}_{3} \mathrm{C}_{2} \mathrm{~T}_{\mathrm{x}}$ exhibited a $105 \%$ increase in the total SE. By contrast, the electrical conductivity of the hybrid buckypaper also increased with the $\mathrm{Ti}_{3} \mathrm{C}_{2} \mathrm{~T}_{\mathrm{x}}$ content (Fig. 5b). A high conductivity of $19,262 \mathrm{~S} \mathrm{~m}^{-1}$ was observed in the hybrid film with $49.4 \mathrm{wt} \% \mathrm{Ti}_{3} \mathrm{C}_{2} \mathrm{~T}_{\mathrm{x}}$, which is $193 \%$ higher than that of pristine CNT buckypaper. The similar increasing trends in the average $\mathrm{SE}_{\text {Total }}$ and electrical conductivity demonstrate that the promotion of electrical conductivity is a major factor for the enhancement of the shielding performance. Further comparisons of $\mathrm{SE}_{\text {Total }}, \mathrm{SE}_{\mathrm{A}}$, and $\mathrm{SE}_{\mathrm{R}}$ are presented in Figs. 5c and S7f. Both the $\mathrm{SE}_{\mathrm{A}}$ and $\mathrm{SE}_{\mathrm{R}}$ in the hybrid buckypapers show a distinct increase with the added $\mathrm{Ti}_{3} \mathrm{C}_{2} \mathrm{~T}_{\mathrm{x}}$ content. Meanwhile, all samples with various $\mathrm{Ti}_{3} \mathrm{C}_{2} \mathrm{~T}_{\mathrm{x}}$ contents retained the absorption-dominant mechanism for EMI shielding.

A high EMI SE can be achieved by simply increasing the thickness. To evaluate the applied value of the EMI shielding materials, the density and thickness of the samples should be considered. The calculated thickness-averaged specific SE value (SSE/t), derived by dividing the SE by the density and thickness, was further investigated (Fig. 5d). Ultrahigh $\mathrm{SSE} / t$ values of over $30,000 \mathrm{~dB} \mathrm{~cm}^{2} \mathrm{~g}^{-1}$ are presented in all 15- $\mu \mathrm{m} \mathrm{Ti}_{3} \mathrm{C}_{2} \mathrm{~T}_{\mathrm{x}} @ \mathrm{CNT}$ hybrid buckypapers with various $\mathrm{Ti}_{3} \mathrm{C}_{2} \mathrm{~T}_{\mathrm{x}}$ content. Among them, the highest SSE/t value of $44,607.3 \mathrm{~dB} \mathrm{~cm}^{2} \mathrm{~g}^{-1}$ is observed in the sample with 26.9 wt $\% \mathrm{Ti}_{3} \mathrm{C}_{2} \mathrm{~T}_{\mathrm{x}}$ (total density of $0.68 \mathrm{~g} \mathrm{~cm}^{-3}$ ), which is $40 \%$ higher than the value of a pristine CNT buckypaper. All of these results demonstrate that the shielding performance of $\mathrm{Ti}_{3} \mathrm{C}_{2} \mathrm{~T}_{\mathrm{x}} @ \mathrm{CNT}$ hybrid buckypapers can be efficiently improved by increasing the $\mathrm{Ti}_{3} \mathrm{C}_{2} \mathrm{~T}_{\mathrm{x}}$ content. Ultrathin and high-performance $\mathrm{Ti}_{3} \mathrm{C}_{2} \mathrm{~T}_{\mathrm{x}} @ \mathrm{CNT}$ hybrid buckypaper for EMI shielding can be effectively constructed.

To further demonstrate the superiority of the $\mathrm{Ti}_{3} \mathrm{C}_{2} \mathrm{~T}_{\mathrm{x}} @$ CNT hybrid buckypaper developed in this work, randomly mixed $\mathrm{Ti}_{3} \mathrm{C}_{2} \mathrm{~T}_{\mathrm{x}} / \mathrm{CNT}$ ( $\mathrm{r}-\mathrm{Ti}_{3} \mathrm{C}_{2} \mathrm{~T}_{\mathrm{x}} / \mathrm{CNTs}$ ) hybrid films were fabricated for comparison. The $\mathrm{r}-\mathrm{Ti}_{3} \mathrm{C}_{2} \mathrm{~T}_{\mathrm{x}} / \mathrm{CNT}$ films were prepared by filtrating the mixed $\mathrm{Ti}_{3} \mathrm{C}_{2} \mathrm{~T}_{\mathrm{x}} / \mathrm{CNT}$ through water dispersion, in which the thicknesses are controlled in $15 \mu \mathrm{m}$. The EMI shielding performances of the $r-\mathrm{Ti}_{3} \mathrm{C}_{2} \mathrm{~T}_{\mathrm{x}} / \mathrm{CNT}$ films 

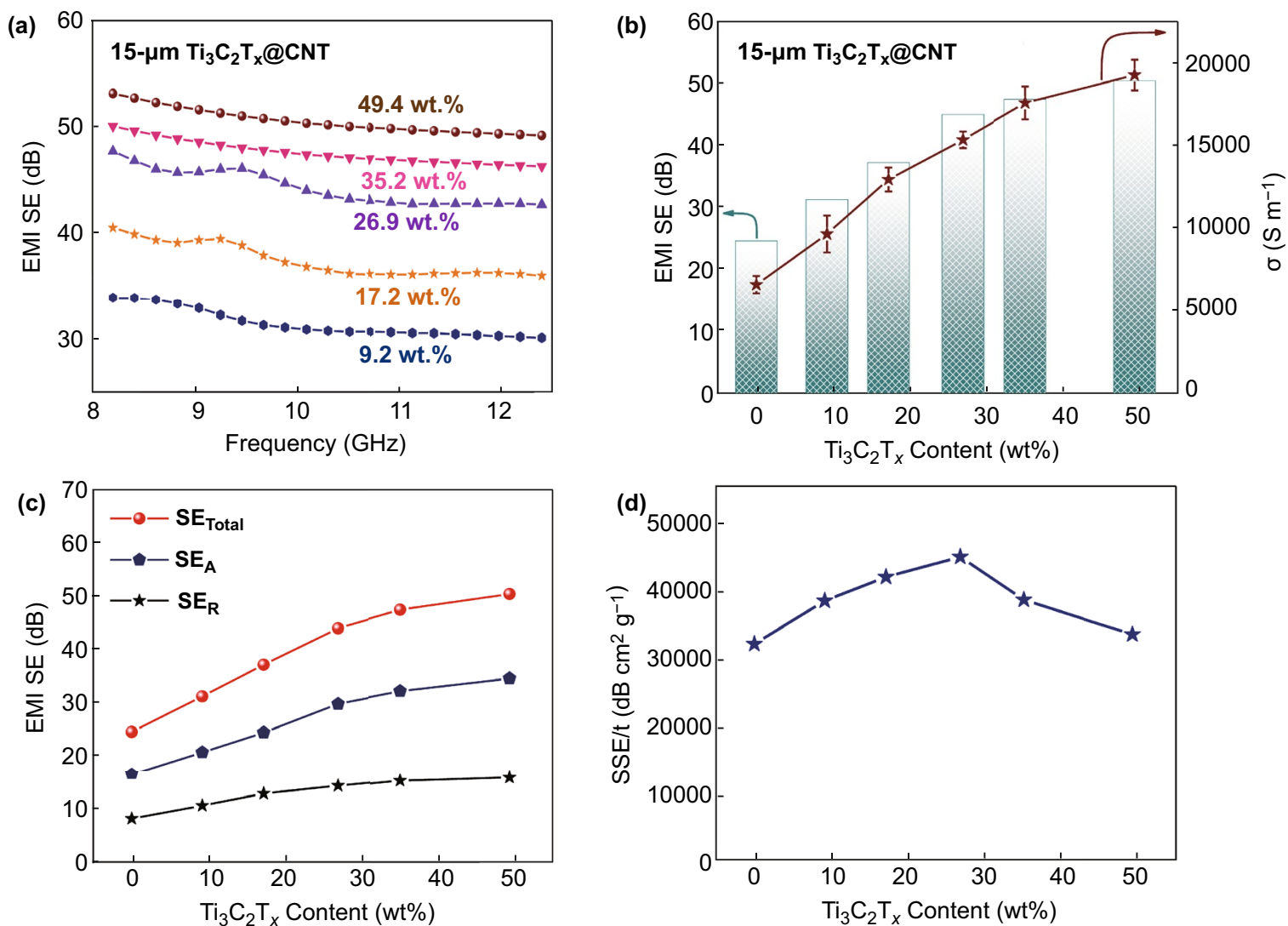

Fig. 5 EMI performance of $\mathrm{Ti}_{3} \mathrm{C}_{2} \mathrm{~T}_{\mathrm{x}} @ \mathrm{CNT}$ hybrid buckypapers with different $\mathrm{Ti}_{3} \mathrm{C}_{2} \mathrm{~T}_{\mathrm{x}}$ content. a EMI SE of 15- $\mu \mathrm{m}$ hybrid buckypapers with different contents of $\mathrm{Ti}_{3} \mathrm{C}_{2} \mathrm{~T}_{\mathrm{x}}$. b Comparison of average $\mathrm{SE}_{\text {Total }}$ and electrical conductivities versus $\mathrm{Ti}_{3} \mathrm{C}_{2} \mathrm{~T}_{\mathrm{x}}$ content in 15- $\mu \mathrm{m}$ hybrid buckypapers. c Comparison of average $\mathrm{SE}_{\mathrm{Tota}}, \mathrm{SE}_{\mathrm{A}}$, and $\mathrm{SE}_{\mathrm{R}}$ versus $\mathrm{Ti}_{3} \mathrm{C}_{2} \mathrm{~T}_{\mathrm{x}}$ content in $15-\mu \mathrm{m}$ hybrid buckypapers. $\mathbf{d} \mathrm{SSE} / \mathrm{t}$ versus $\mathrm{Ti}_{3} \mathrm{C}_{2} \mathrm{~T}_{\mathrm{x}}$ content in $15-\mu \mathrm{m}$ hybrid buckypapers

with different $\mathrm{Ti}_{3} \mathrm{C}_{2} \mathrm{~T}_{\mathrm{x}}$ contents are shown in Fig. S8a-e. This is consistent with those reported in $[9,31]$. The SE of $\mathrm{r}-\mathrm{Ti}_{3} \mathrm{C}_{2} \mathrm{~T}_{\mathrm{x}} / \mathrm{CNT}$ films also shows an obvious increase with the addition of $\mathrm{Ti}_{3} \mathrm{C}_{2} \mathrm{~T}_{\mathrm{x}}$ content. However, the increasing trend in the $\mathrm{r}-\mathrm{Ti}_{3} \mathrm{C}_{2} \mathrm{~T}_{\mathrm{x}} / \mathrm{CNT}$ film is much lower than that of the $\mathrm{Ti}_{3} \mathrm{C}_{2} \mathrm{~T}_{\mathrm{x}} @ \mathrm{CNT}$ hybrid buckypaper (Fig. S8f). When the $\mathrm{Ti}_{3} \mathrm{C}_{2} \mathrm{~T}_{\mathrm{x}} @ \mathrm{CNT}$ hybrid buckypaper with $49.4 \mathrm{wt} \% \mathrm{Ti}_{3} \mathrm{C}_{2} \mathrm{~T}_{\mathrm{x}}$ shows a high SE of $50.4 \mathrm{~dB}$, the value of an $\mathrm{r}-\mathrm{Ti}_{3} \mathrm{C}_{2} \mathrm{~T}_{\mathrm{x}} / \mathrm{CNT}$ film with $60 \mathrm{wt} \% \mathrm{Ti}_{3} \mathrm{C}_{2} \mathrm{~T}_{\mathrm{x}}$ is only $36.9 \mathrm{~dB}$. The relatively low shielding performance of the $\mathrm{r}-\mathrm{Ti}_{3} \mathrm{C}_{2} \mathrm{~T}_{\mathrm{x}} / \mathrm{CNT}$ film may be attributed to the unordered stacking structure. The overstacking of $\mathrm{Ti}_{3} \mathrm{C}_{2} \mathrm{~T}_{\mathrm{x}}$ nanoflakes will weaken the connection in the components, resulting in low conductivity and thus low shielding performance. In this work, through a simple electrophoretic deposition process, the $\mathrm{Ti}_{3} \mathrm{C}_{2} \mathrm{~T}_{\mathrm{x}}$ nanoflakes can be well dispersed in the CNT network. Each piece of nanoflake is well connected to the carbon nanotubes. The resulting continuous conductive network leads to an outstanding EMI shielding performance.

The proposed EMI shielding mechanism in the $\mathrm{Ti}_{3} \mathrm{C}_{2} \mathrm{~T}_{\mathrm{x}} @$ CNT hybrid buckypaper is illustrated in Fig. 6a. When the electromagnetic waves reach the surface of the hybrid buckypaper, a portion of the incident waves are immediately reflected back, which is attributed to the high conductivity of the hybrid film. The remaining incident waves continuously spread into the hybrid buckypaper and interact with the high electron density of the CNT-Ti ${ }_{3} \mathrm{C}_{2} \mathrm{~T}_{\mathrm{x}}$ network, resulting in ohmic loss and energy dissipation. Meanwhile, the well-separated $\mathrm{Ti}_{3} \mathrm{C}_{2} \mathrm{~T}_{\mathrm{x}}$ nanoflakes and the formed microfissures in the CNT- $\mathrm{Ti}_{3} \mathrm{C}_{2} \mathrm{~T}_{\mathrm{x}}$ network provided an abundant air-solid interface for multiple internal reflections and interface polarization loss. The electromagnetic waves are repeatedly reflected inside the $\mathrm{CNT}-\mathrm{Ti}_{3} \mathrm{C}_{2} \mathrm{~T}_{\mathrm{x}}$ network until they are completely absorbed. Moreover, the abundant defects 

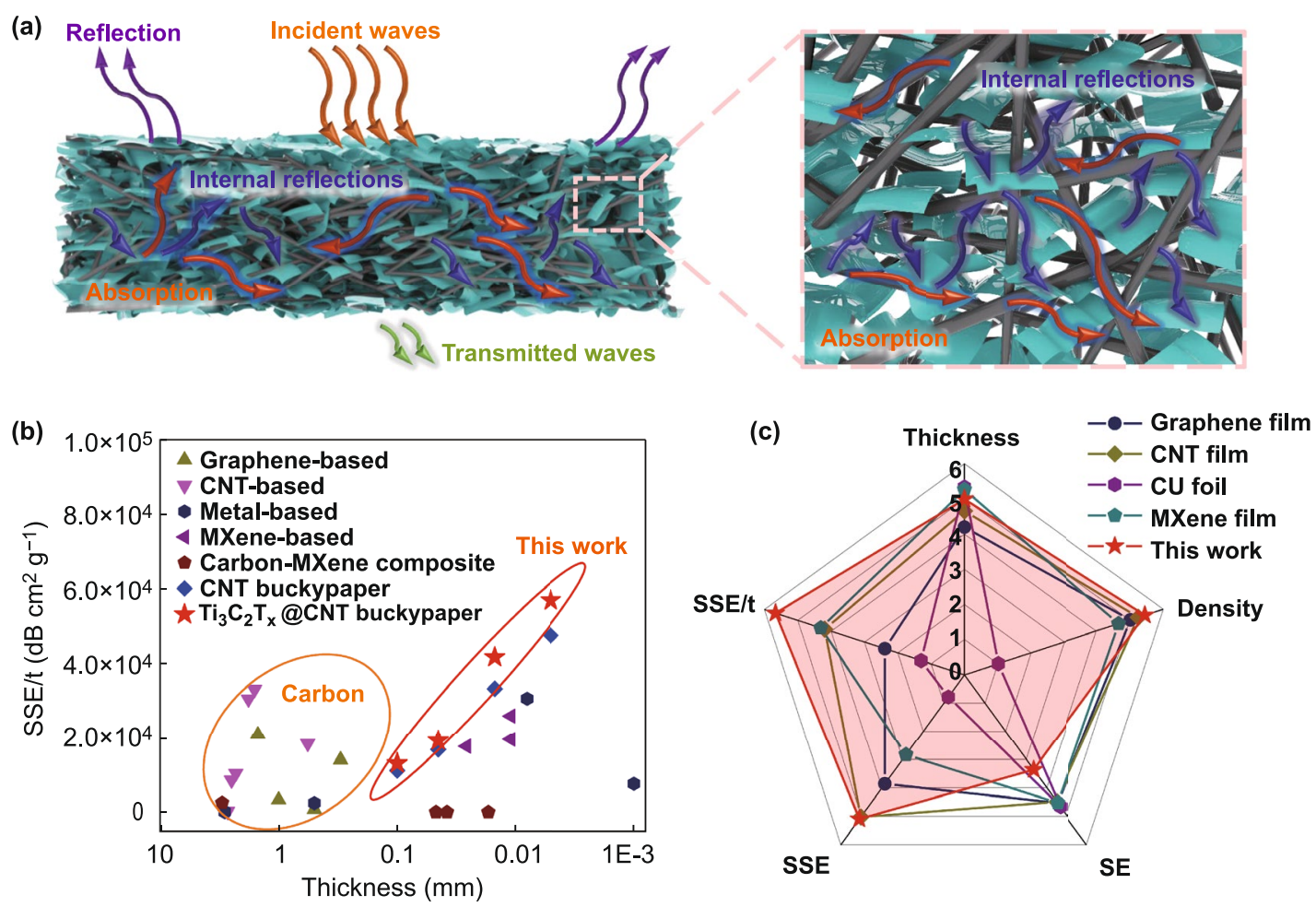

Fig. 6 a Proposed EMI shielding mechanism of $\mathrm{Ti}_{3} \mathrm{C}_{2} \mathrm{~T}_{\mathrm{x}} @ \mathrm{CNT}$ hybrid buckypaper. b Comparison of SSE/t versus thickness in Ti ${ }_{3} \mathrm{C}_{2} \mathrm{~T}_{\mathrm{x}} @ \mathrm{CNT}$ hybrid buckypapers and other shielding materials. Detailed data thereof are listed in Table S1. c Radar chart for comparison of thickness, density, SE, SSE, and SSE/t in the optimized 15- $\mu \mathrm{m} \mathrm{Ti}_{3} \mathrm{C}_{2} \mathrm{~T}_{\mathrm{x}} @ \mathrm{CNT}$ hybrid buckypaper and the other reported ultrathin EMI shielding films with a thickness of 11-27 $\mu \mathrm{m}$, in which the five dimensions are divided into six grades. In particular, high grades in thickness and density mean low values. Detailed data thereof are listed in Table $\mathrm{S} 2$

in the slightly etched carbon nanotubes and $\mathrm{Ti}_{3} \mathrm{C}_{2} \mathrm{~T}_{\mathrm{x}}$ nanoflakes also lead to an asymmetric distribution of electrons and thus dielectric loss [31, 40]. All of these factors result in a high EMI shielding performance in the $\mathrm{Ti}_{3} \mathrm{C}_{2} \mathrm{~T}_{\mathrm{x}} @ \mathrm{CNT}$ hybrid film.

To objectively evaluate the practicality, the EMI SE values and thickness-averaged SSE/t values of $\mathrm{Ti}_{3} \mathrm{C}_{2} \mathrm{~T}_{\mathrm{x}} @ \mathrm{CNT}$ hybrid buckypapers are compared with those of other materials in Figs. $6 \mathrm{~b}$ and $\mathrm{S} 9$ (the detailed data thereof are listed in Table S1). Although the reported graphene-based [6, 7, 10, 41] and CNT-based composites [4, 12, 42, 43] exhibit a high EMI SE, they all present a relatively low SSE/t owing to their high thickness. The dense metal-based film [24, 44, 45], $\mathrm{Ti}_{3} \mathrm{C}_{2} \mathrm{~T}_{\mathrm{x}}$ film [24], and $\mathrm{Ti}_{3} \mathrm{C}_{2} \mathrm{~T}_{\mathrm{x}}$ /polymer film [20, 21] exhibit a high EMI SE with a small thickness. However, the high densities result in low SSE/t values. Some reported $\mathrm{Ti}_{3} \mathrm{C}_{2} \mathrm{~T}_{\mathrm{x}} /$ carbon composites show both a high mechanical strength and shielding performance [1, 9, 28, 31]. However, their high thickness or high density still leads to a low SSE/t. The $\mathrm{Ti}_{3} \mathrm{C}_{2} \mathrm{~T}_{\mathrm{x}} @ \mathrm{CNT}$ hybrid buckypapers developed in this work reached a balance of a relatively low density, low thickness, and high SE. All these factors contribute to the high $\mathrm{SSE} / \mathrm{t}$ value $\left(13,074.2-56,945.8 \mathrm{~dB} \mathrm{~cm}^{2} \mathrm{~g}^{-1}\right)$.

A satisfactory commercial EMI shielding film requires not only a high SE, but also a small thickness, low density, and high SSE and SSE/t. The 15- $\mu \mathrm{m} \mathrm{Ti}_{3} \mathrm{C}_{2} \mathrm{~T}_{\mathrm{x}} @ \mathrm{CNT}$ hybrid buckypaper with $49.4 \mathrm{wt} \% \mathrm{Ti}_{3} \mathrm{C}_{2} \mathrm{~T}_{\mathrm{x}}$ described in this work is compared with the reported ultrathin EMI shielding films $(10-30 \mu \mathrm{m})$ such as a graphene film [46], CNT film [47], $\mathrm{Cu}$ foil [24], and MXene film [24] in terms of five dimensions (thickness, density, SE, SSE, and SSE/t). A radar chart, in which the five dimensions are divided into six grades (in particular, high grades in thickness and density mean low values), is shown in Fig. 6c. Detailed data thereof are shown in Table S2. The high SE in these ultrathin EMI shielding films relies on the high densities. At similar thicknesses, they all show a relatively low SSE and SSE/t. For instance, although the $\mathrm{Cu}$ foil shows a high EMI SE of $70 \mathrm{~dB}$ in a small thickness of $10 \mu \mathrm{m}$, its density is as high as $9.87 \mathrm{~g} \mathrm{~cm}^{-3}$. Thus, the $\mathrm{Cu}$ foil exhibits a relatively low SSE of $7.8 \mathrm{~dB} \mathrm{~cm}^{3} \mathrm{~g}^{-1}$ and 
SSE/t of $7812 \mathrm{~dB} \mathrm{~cm}^{2} \mathrm{~g}^{-1}$. By contrast, the $15-\mu \mathrm{m} \mathrm{Ti}_{3} \mathrm{C}_{2} \mathrm{~T}_{\mathrm{x}} @$ CNT hybrid buckypaper with $49.4 \mathrm{wt} \% \mathrm{Ti}_{3} \mathrm{C}_{2} \mathrm{~T}_{\mathrm{x}}$ in this work shows a satisfactory EMI SE of $50.4 \mathrm{~dB}$ with a relative low density of $0.98 \mathrm{~g} \mathrm{~cm}^{-3}$. Therefore, a high SSE of $51.0 \mathrm{~dB}$ $\mathrm{cm}^{3} \mathrm{~g}^{-1}$ and SSE/t of $34,003.7 \mathrm{~dB} \mathrm{~cm}^{2} \mathrm{~g}^{-1}$ are achieved. The high SSE and SSE/t in the hybrid buckypaper may be attributed to the well-designed internal microstructure.

\section{Conclusions}

In this study, we report an efficient electrophoretic deposition process to construct a flexible, lightweight, and ultrathin $\mathrm{Ti}_{3} \mathrm{C}_{2} \mathrm{~T}_{\mathrm{x}} @ \mathrm{CNT}$ hybrid buckypaper with high EMI shielding performance. The homogeneously filled $\mathrm{Ti}_{3} \mathrm{C}_{2} \mathrm{~T}_{\mathrm{x}}$ nanoflakes effectively improved both the reflection and absorption of the electromagnetic wave in the hybrid film. An $\mathrm{SE}_{\text {Total }}$ of $60.5 \mathrm{~dB}$ was yielded within the X-band for the $100-\mu \mathrm{m}$ hybrid buckypaper. Meanwhile, increasing the MXene content can effectively enhance the SE. Moreover, a distinguished SSE/ $t$ value of $56,945.8 \mathrm{~dB} \mathrm{~cm}^{2} \mathrm{~g}^{-1}$ was exhibited in the 5- $\mu \mathrm{m}$ hybrid buckypaper. Thus, flexible and ultrathin $\mathrm{Ti}_{3} \mathrm{C}_{2} \mathrm{~T}_{\mathrm{x}} @ \mathrm{CNT}$ hybrid buckypapers with an outstanding EMI shielding performance have significant applications in the fields of smart and wearable electronic devices.

Acknowledgements This work was financially supported by National Natural Science Foundation of China (Grant Nos. 52072415, 52072306 and 51772335), the Science and Technology Program of Guangzhou (201904010450), Science Foundation of the National Key Laboratory of Science and Technology on Advanced Composites in Special Environments (6142905192509).

Open Access This article is licensed under a Creative Commons Attribution 4.0 International License, which permits use, sharing, adaptation, distribution and reproduction in any medium or format, as long as you give appropriate credit to the original author(s) and the source, provide a link to the Creative Commons licence, and indicate if changes were made. The images or other third party material in this article are included in the article's Creative Commons licence, unless indicated otherwise in a credit line to the material. If material is not included in the article's Creative Commons licence and your intended use is not permitted by statutory regulation or exceeds the permitted use, you will need to obtain permission directly from the copyright holder. To view a copy of this licence, visit http://creativecommons.org/licenses/by/4.0/.

Supplementary Information The online version contains supplementary material available at https://doi.org/10.1007/s4082 0-021-00597-4.

\section{References}

1. W.T. Cao, F.F. Chen, Y.J. Zhu, Y.G. Zhang, Y.Y. Jiang et al., Binary strengthening and toughening of MXene/cellulose nanofiber composite paper with nacre-inspired structure and superior electromagnetic interference shielding properties. ACS Nano 12, 4583-4593 (2018). https://doi.org/10.1021/ acsnano.8b00997

2. M. Hu, C. Cui, C. Shi, Z.S. Wu, J. Yang et al., High-energydensity hydrogen-ion-rocking-chair hybrid supercapacitors based on $\mathrm{Ti}_{3} \mathrm{C}_{2} \mathrm{~T}_{\mathrm{x}}$ MXene and carbon nanotubes mediated by redox active molecule. ACS Nano 13, 6899 (2019). https://doi. org/10.1021/acsnano.9b01762

3. Y. Chen, H.B. Zhang, Y. Yang, M. Wang, A. Cao et al., Highperformance epoxy nanocomposites reinforced with threedimensional carbon nanotube sponge for electromagnetic interference shielding. Adv. Funct. Mater. 26, 447-455 (2016). https://doi.org/10.1002/adfm.201503782

4. P. Hu, J. Lyu, C. Fu, W.B. Gong, J. Liao et al., Multifunctional aramid nanofiber/carbon nanotube hybrid aerogel films. ACS Nano 14, 688-697 (2020). https://doi.org/10.1021/acsna no. 9 b0 07459

5. Z. Zeng, H. Jin, M. Chen, W. Li, L. Zhou et al., Microstructure design of lightweight, flexible, and high electromagnetic shielding porous multiwalled carbon nanotube/polymer composites. Small 13, 201701388 (2017). https://doi.org/10.1002/ smll.201701388

6. Z. Chen, C. Xu, C. Ma, W. Ren, H.M. Cheng, Lightweight and flexible graphene foam composites for high-performance electromagnetic interference shielding. Adv. Mater. 25, 1296-1300 (2013). https://doi.org/10.1002/adma.201204196

7. Y. Wu, Z. Wang, X. Liu, X. Shen, Q. Zheng et al., Ultralight graphene foam/conductive polymer composites for exceptional electromagnetic interference shielding. ACS Appl. Mater. Interfaces 9, 9059-9069 (2017). https://doi.org/10.1021/acsam i. $7 b 01017$

8. C. Weng, G. Wang, Z. Dai, Y. Pei, L. Liu et al., Buckled AgNW/MXene hybrid hierarchical sponges for high-performance electromagnetic interference shielding. Nanoscale 11, 22804-22812 (2019). https://doi.org/10.1039/c9nr07988b

9. P. Sambyal, A. Iqbal, J. Hong, H. Kim, M.K. Kim et al., Ultralight and mechanically robust $\mathrm{Ti}_{3} \mathrm{C}_{2} \mathrm{~T}_{\mathrm{x}}$ hybrid aerogel reinforced by carbon nanotubes for electromagnetic interference shielding. ACS Appl. Mater. Interfaces 11, 38046-38054 (2019). https://doi.org/10.1021/acsami.9b12550

10. J. Liu, Y. Liu, H.B. Zhang, Y. Dai, Z. Liu et al., Superelastic and multifunctional graphene based aerogels by interfacial reinforcement with graphitized carbon at high temperatures. Carbon 132, 95-103 (2018). https://doi.org/10.1016/j.carbo n.2018.02.026

11. Q. Song, F. Ye, X. Yin, W. Li, H. Li et al., Carbon nanotubemultilayered graphene edge plane core-shell hybrid foams for ultrahigh-performance electromagnetic-interference shielding. Adv. Mater. 29, 201701583 (2017). https://doi.org/10.1002/ adma. 201701583 
12. D. Lu, Z. Mo, B. Liang, L. Yang, Z. He et al., Flexible, lightweight carbon nanotube sponges and composites for high-performance electromagnetic interference shielding. Carbon 133, 457-463 (2018). https://doi.org/10.1016/j.carbon.2018.03.061

13. Y. Zhan, J. Wang, K. Zhang, Y. Li, Y. Meng et al., Fabrication of a flexible electromagnetic interference shielding $\mathrm{Fe}_{3} \mathrm{O}_{4} @$ reduced graphene oxide/natural rubber composite with segregated network. Chem. Eng. J. 344, 184-193 (2018). https:// doi.org/10.1016/j.cej.2018.03.085

14. S. Wu, M. Zou, Z. Li, D. Chen, H. Zhang et al., Robust and stable $\mathrm{Cu}$ nanowire@graphene core-shell aerogels for ultraeffective electromagnetic interference shielding. Small 14, 201800634 (2018). https://doi.org/10.1002/smll.20180 0634

15. J. Jung, H. Lee, I. Ha, H. Cho, K.K. Kim et al., Highly stretchable and transparent electromagnetic interference shielding film based on silver nanowire percolation network for wearable electronics applications. ACS Appl. Mater. Interfaces 9, 44609 (2017). https://doi.org/10.1021/acsam i. 7 b1 14626

16. M.S. Cao, Y.Z. Cai, P. He, J.C. Shu, W.Q. Cao et al., 2D MXenes: electromagnetic property for microwave absorption and electromagnetic interference shielding. Chem. Eng. J. 359, 1265-1302 (2019). https://doi.org/10.1016/j.cej.2018.11.051

17. M. Han, C.E. Shuck, R. Rakhmanov, D. Parchment, B. Anasori et al., Beyond $\mathrm{Ti}_{3} \mathrm{C}_{2} \mathrm{~T}_{\mathrm{x}}$ : MXenes for electromagnetic interference shielding. ACS Nano 14, 5008-5016 (2020). https://doi. org/10.1021/acsnano.0c01312

18. T. Yun, H. Kim, A. Iqbal, Y.S. Cho, G.S. Lee et al., Electromagnetic shielding of monolayer MXene assemblies. Adv. Mater. 32, 201906769 (2020). https://doi.org/10.1002/ adma.201906769

19. H. Chen, Y. Wen, Y. Qi, Q. Zhao, L. Qu et al., Pristine titanium carbide mxene films with environmentally stable conductivity and superior mechanical strength. Adv. Funct. Mater. 30, 201906996 (2020). https://doi.org/10.1002/adfm.201906996

20. R. Liu, M. Miao, Y. Li, J. Zhang, S. Cao et al., Ultrathin biomimetic polymeric $\mathrm{Ti}_{3} \mathrm{C}_{2} \mathrm{~T}_{\mathrm{x}}$ MXene composite films for electromagnetic interference shielding. ACS Appl. Mater. Interfaces 10, 44787-44795 (2018). https://doi.org/10.1021/acsam i. 8 b 18347

21. Z. Zhou, J. Liu, X. Zhang, D. Tian, Z. Zhan et al., Ultrathin MXene/calcium alginate aerogel film for high-performance electromagnetic interference shielding. Adv. Mater. Interfaces 6, 201802040 (2019). https://doi.org/10.1002/admi.201802040

22. Y.J. Wan, X.M. Li, P.L. Zhu, R. Sun, C.P. Wong et al., Lightweight, flexible MXene/polymer film with simultaneously excellent mechanical property and high-performance electromagnetic interference shielding. Compos. Part A 130, 105764 (2020). https://doi.org/10.1016/j.compositesa.2020.105764

23. X. Jin, J. Wang, L. Dai, X. Liu, L. Li et al., Flame-retardant poly(vinyl alcohol)/mxene multilayered films with outstanding electromagnetic interference shielding and thermal conductive performances. Chem. Eng. J. 380, 122475 (2020). https://doi. org/10.1016/j.cej.2019.122475
24. F. Shahzad, M. Alhabeb, C.B. Hatter, B. Anasori, S.M. Hong et al., Electromagnetic interference shielding with 2D transition metal carbides (MXenes). Science 353, 1137-1140 (2016). https://doi.org/10.1126/science.aag2421

25. A. Iqbal, F. Shahzad, K. Hantanasirisakul, M.K. Kim, J. Kwon et al., Anomalous absorption of electromagnetic waves by $2 \mathrm{D}$ transition metal carbonitride $\mathrm{Ti}_{3} \mathrm{CNT}_{\mathrm{x}}(\mathrm{MXene})$. Science 369, 446 (2020). https://doi.org/10.1126/science.aba7977

26. J. Lipton, G.M. Weng, J.A. Röhr, H. Wang, A.D. Taylor, Layer-by-layer assembly of two-dimensional materials: meticulous control on the nanoscale. Matter 2, 1148-1165 (2020). https://doi.org/10.1016/j.matt.2020.03.012

27. X. Zang, J. Wang, Y. Qin, T. Wang, C. He et al., Enhancing capacitance performance of MXene as electrode materials of supercapacitor: from controlled preparation to composite structure construction. Nano-Micro Lett. 12, 77 (2020). https ://doi.org/10.1007/s40820-020-0415-5

28. F. Xie, F. Jia, L. Zhuo, Z. Lu, L. Si et al., Ultrathin MXene/ aramid nanofiber composite paper with excellent mechanical properties for efficient electromagnetic interference shielding. Nanoscale 11, 23382-23391 (2019). https://doi.org/10.1039/ c9nr07331k

29. Y. Li, X. Tian, S.P. Gao, L. Jing, K. Li et al., Reversible crumpling of 2D titanium carbide (MXene) nanocoatings for stretchable electromagnetic shielding and wearable wireless communication. Adv. Funct. Mater. 30, 201907451 (2020). https://doi.org/10.1002/adfm.201907451

30. Z. Zeng, C. Wang, G. Siqueira, D. Han, A. Huch et al., Nanocellulose-MXene biomimetic aerogels with orientation-tunable electromagnetic interference shielding performance. Adv. Sci. 7, 202000979 (2020). https://doi.org/10.1002/advs.20200 0979

31. W. Cao, C. Ma, S. Tan, M. Ma, P. Wan et al., Ultrathin and flexible CNTs/MXene/cellulose nanofibrils composite paper for electromagnetic interference shielding. Nano-Micro Lett. 11, 72 (2019). https://doi.org/10.1007/s40820-019-0304-y

32. J. Liu, Z. Liu, H.B. Zhang, W. Chen, Z. Zhao et al., Ultrastrong and highly conductive MXene-based films for highperformance electromagnetic interference shielding. Adv. Electron. Mater. 6, 201901094 (2020). https://doi.org/10.1002/ aelm.201901094

33. G.M. Weng, J. Li, M. Alhabeb, C. Karpovich, H. Wang et al., Layer-by-layer assembly of cross-functional semi-transparent MXene-carbon nanotubes composite films for next-generation electromagnetic interference shielding. Adv. Funct. Mater. 28, 201803360 (2018). https://doi.org/10.1002/adfm.201803360

34. B. Zhou, Z. Zhang, Y. Li, G. Han, Y. Feng et al., Robust, and multifunctional electromagnetic interference shielding film with alternating cellulose nanofiber and MXene layers. ACS Appl. Mater. Interfaces 12, 4895-4905 (2020). https://doi. org/10.1021/acsami.9b19768

35. Z. Ma, S. Kang, J. Ma, L. Shao, Y. Zhang et al., Ultraflexible and mechanically strong double-layered aramid nanofiber$\mathrm{Ti}_{3} \mathrm{C}_{2} \mathrm{~T}_{\mathrm{x}} \mathrm{MXene/silver} \mathrm{nanowire} \mathrm{nanocomposite} \mathrm{papers} \mathrm{for}$ high-performance electromagnetic interference shielding. 
ACS Nano 14, 8368-8382 (2020). https://doi.org/10.1021/ acsnano.0c02401

36. A.G. Cano-Márquez, F.J. Rodríguez-Macías, J. Campos-Delgado, C.G. Espinosa-González, F. Tristán-López et al., ExMWNTs: graphene sheets and ribbons produced by lithium intercalation and exfoliation of carbon nanotubes. Nano Lett. 9, 1527-1533 (2009). https://doi.org/10.1021/nl803585s

37. J. Lim, U.N. Maiti, N.Y. Kim, R. Narayan, W.J. Lee et al., Dopant-specific unzipping of carbon nanotubes for intact crystalline graphene nanostructures. Nat. Commun. 7, 10364 (2016). https://doi.org/10.1038/ncomms 10364

38. S. Yang, P. Zhang, F. Wang, A.G. Ricciardulli, M.R. Lohe et al., fluoride-free synthesis of two-dimensional titanium carbide (MXene) using a binary aqueous system. Angew. Chem. Int. Ed. 57, 15491-15495 (2018). https://doi.org/10.1002/ anie. 201809662

39. T. Schultz, N.C. Frey, K. Hantanasirisakul, S. Park, S.J. May et al., Surface termination dependent work function and electronic properties of $\mathrm{Ti}_{3} \mathrm{C}_{2} \mathrm{~T}_{\mathrm{x}}$ MXene. Chem. Mater. 31, 65906597 (2019). https://doi.org/10.1021/acs.chemmater.9b00414

40. C. Cui, C. Xiang, L. Geng, X. Lai, R. Guo et al., Flexible and ultrathin electrospun regenerate cellulose nano fibers and $\mathrm{D}-\mathrm{Ti}_{3} \mathrm{C}_{2} \mathrm{~T}_{\mathrm{x}}$ ( MXene ) composite film for electromagnetic interference shielding. J. Alloys Compd. 788, 1246-1255 (2019). https://doi.org/10.1016/j.jallcom.2019.02.294

41. B. Shen, Y. Li, D. Yi, W. Zhai, X. Wei et al., Microcellular graphene foam for improved broadband electromagnetic interference shielding. Carbon 102, 154-160 (2016). https://doi. org/10.1016/j.carbon.2016.02.040
42. Y.J. Tan, J. Li, J.H. Cai, X.H. Tang, J.H. Liu et al., Comparative study on solid and hollow glass microspheres for enhanced electromagnetic interference shielding in polydimethylsiloxane/multi-walled carbon nanotube composites. Compos. Part B 177, 107378 (2019). https://doi.org/10.1016/j.composites b. 2019.107378

43. M. Li, L. Jia, X. Zhang, D. Yan, Q. Zhang et al., Robust carbon nanotube foam for efficient electromagnetic interference shielding and microwave absorption. J. Colloid Interface Sci. 530, 113-119 (2018). https://doi.org/10.1016/j. jcis.2018.06.052

44. X. Shui, D.D.L. Chung, Nickel filament polymer-matrix composites with low surface impedance and high electromagnetic interference shielding effectiveness. J. Electron. Mater. 26, 928-934 (1997). https://doi.org/10.1007/s11664-997-0276-4

45. J. Ma, K. Wang, M. Zhan, A comparative study of structure and electromagnetic interference shielding performance for silver nanostructure hybrid polyimide foams. RSC Adv. 5, 65283-65296 (2015). https://doi.org/10.1039/c5ra09507g

46. E. Zhou, J. Xi, Y. Liu, Z. Xu, Y. Guo et al., Large-area potassium-doped highly conductive graphene films for electromagnetic interference shielding. Nanoscale 9, 18613-18618 (2017). https://doi.org/10.1039/c7nr07030f

47. H. Li, X. Lu, D. Yuan, J. Sun, F. Erden et al., Lightweight flexible carbon nanotube/polyaniline films with outstanding EMI shielding properties. J. Mater. Chem. C 5, 8694-8698 (2017). https://doi.org/10.1039/c7tc02394d 